\title{
Small Scale Low Height Wave Energy Seawater Pump for Achieving Environmental and Economic Sustainability
}

\author{
Man Djun Lee*, Ellis Ling Kang Feng, Pui San Lee \\ School of Engineering and Technology, University College of Technology Sarawak, Malaysia
}

Received October 24, 2019; Revised November 28, 2019; Accepted December 4, 2019

Copyright $\mathrm{O} 2020$ by authors, all rights reserved. Authors agree that this article remains permanently open access under the terms of the Creative Commons Attribution License 4.0 International License

\begin{abstract}
This study is about the design and development of seawater pump powered by low height sea wave at near shore region. This study focuses on developing seawater pump that does not use any electricity for delivering high pressure saline water to on shore region which is in line with the global renewable energy quest. Malaysia is blessed with the geographic location of surrounded by sea which enables this technology to be utilized. The challenge in utilizing such technology is due to the nature of the sea wave surrounding Malaysia that is classified as low height sea wave which increase the difficulty in utilizing such technology in neither electricity generation nor sea water delivery. On top of that, there is limited study available in this area especially low wave height. The prototype is designed based on point absorber concept with piston type pump configuration for water delivery. Then the prototype is tested at the Mukah Beach with average recorded wave height of less than $1 \mathrm{~m}$. Findings demonstrated that a single prototype pump is capable of delivering maximum pressure head of $10 \mathrm{~m}$ with maximum flow of 1.2Litre per minute (LPM). For three pumps connected in series, the maximum pressure head can reach up to $25 \mathrm{~m}$ pressure head with maximum flow rate of 1.5LPM. Similarly, when connected in parallel, the system is capable to deliver up to $14 \mathrm{~m}$ of pressure head and 3LPM of flow rate. The findings indicate that the prototype is significant for seawater delivering. Although the output of the prototype is small, its potential is yet to be fully unleashed. Therefore, it is highly recommended for future study the prototype to be pair together with more similar pumps in series or parallel configurations to form a system of pumps to create higher flow and higher head for more application. This study concludes that the designed and developed prototype is useful for delivering saline water for various application such as seawater desalination or electricity generation in near shore area or islands.
\end{abstract}

Keywords Piston Pump, Renewable Energy, Point Absorber, Low Height Sea Wave

\section{Introduction}

Wave energy is a promising source of renewable energy to meet rapid growing demand for energy (Pecher \& Kofoed 2017). Recently, many types of ocean power converters have been developed. However, most prototype were specifically designed for local sea where it was planned for (Joe et al. 2017). This indicates that most suitable technology to extract energy is not defined yet. Even though wave energy technologies are in its infancy, this industry is getting more attention due to factors such as highest energy density among other renewable energy sources, less negative impact to the environment, and predictable (Yurchenko \& Alevras 2018). Being surrounded by sea granted Malaysia access to such renewable energy. This study intends to explore and extract energy from sea wave to pump sea water to shore for various purposes such as desalination or power generation or both. This study focused on the design and development pump driven by wave energy to deliver water from sea source to shore without electricity. In this aspect, the following are the research questions to be addressed in this work:

1. What is the design suitable to capture energy from sea wave to deliver sea water to shore?

2. What is the performance of the proposed design?

This is a fundamental research in ocean engineering domain. Through experiment and model development the outcome of this study would contribute to add knowledge in the current domain of ocean engineering. The outcome of this study can be applied seawater desalination and 
power generation.

\section{Literature Review}

Waves are created by wind, gravitational pull of the sun and moon on earth (Rodrigues 2008). Waves move in a circular motion due to energy passing through water. Waves formed are categorised as energy as it transmits energy but not water. They do have high potential to travel across entire ocean basin. Waves formed are cause by the friction between the wind and water surface. When the wind blow across the surface of water, it will create a wave crest. Wave scale may be caused by weather, once the storm coming, it causes storm surge and a continue long wave will be created far from shore in deeper water and become even stronger when near to the land. It also can be caused by underwater disturbances such as earthquakes, landslides, or volcanic eruptions under the deep sea (Rodrigues 2008). Typical ocean waves classifications based on period band, generating forces and restoring forces are summarized in Table 1.

The most commonly available waves are wind sea and swell (Figure 1). As the wavelength is excess $1.5 \mathrm{~m}$ with the wave period more than $1 \mathrm{~s}$, the surface tension will be negligible, and gravity remains the sole restoring mechanism. In this case the wave is named as gravity wave. It has the wave period about 1s and up to maximum wave period to $25 \mathrm{~s}$ with the wavelength about $1.5 \mathrm{~m}$ to $900 \mathrm{~m}$. The direct effect of the local wind causing a large number of elements with various wave period, propagations, direction and phases will be generated. One of the waves produced with an irregular wave pattern is named as Wind Sea. Wind Sea has wavelength of $22 \mathrm{~m}$ to $150 \mathrm{~m}$ with a wave period approximately $10 \mathrm{~s}$ to $12 \mathrm{~s}$. There is another wave formed which called Swells. Swells is formed when waves propagate over a depth (infinite depth) that is larger than wavelength, shorter wave travel slower than the faster one, and they distribute each other. Swells have wavelength $260 \mathrm{~m}$ with period $13 \mathrm{~s}$ and up to maximum about $900 \mathrm{~m}$ with the period time 24s (Illesinghe et al. 2017).

The wave will continue the motion of up and down, this means the movement of energy (kinetic energy) had been transferred to the water particles. When the water particle moves further from their original position which is move up towards to the crest or down to the trough, this will show the kinetic energy of water particle started to convert into potential energy, the motion of water particles are named as wave oscillation (Figure 2).

Table 1. Ocean wave classification (Hong et al. 2014)

\begin{tabular}{|l|l|l|l|}
\hline Classification (Waves) & Period Band (S) & Generating Forces & Restoring Forces \\
\hline Capillary & $<0.1$ & Wind & Surface tension \\
\hline Ultra-gravity & -1 & wind & Surface tension and gravity \\
\hline Gravity & $1-20$ & Wind & Gravity \\
\hline Infra-gravity & $20-300$ & Wind and atmospheric pressure gradients & Gravity \\
\hline Long-period & $300-43200$ & Atmospheric pressure gradients and earth quake & Gravity \\
\hline Ordinary Tidal & $43200-518400$ & Gravitational attraction & Gravity and Coriolis force \\
\hline Trans-tidal & $>518400$ & Storms and gravitational attraction & Gravity and Coriolis force \\
\hline
\end{tabular}

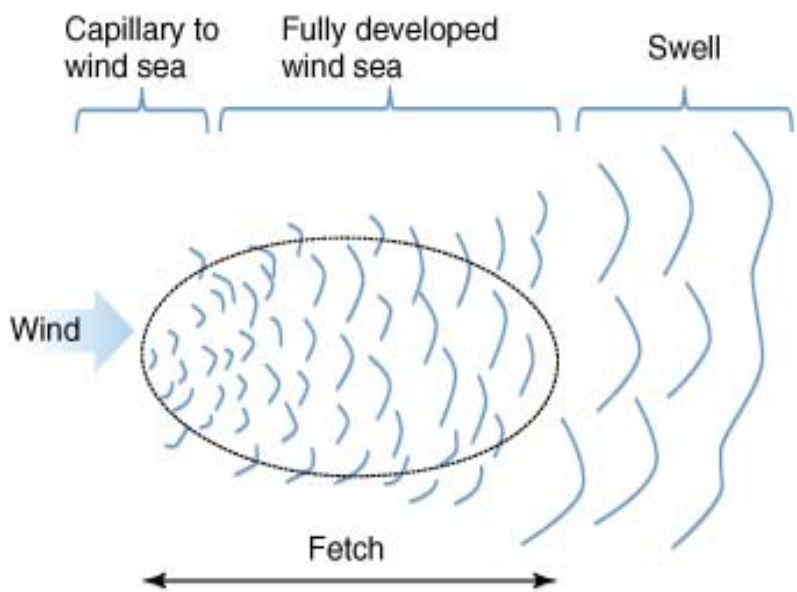

Figure 1. Wind sea and swell propagation mechanism (Illesinghe et al. 2017) 


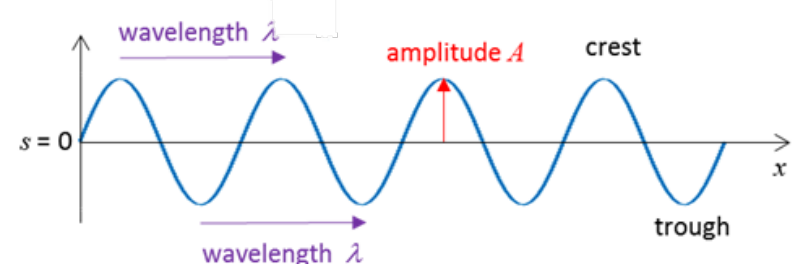

Figure 2. Wave motion (Leijon et al. 2006)

The maximum disturbance of a wave from mid-point between the crest and trough is named as amplitude A, the maximum point of a wave is called crest and the minimum point in a wave is named as trough. The energy carried by wave is proportional to the square of the wave amplitude. The kinetic energy can be determined by Equation (1).

$$
\text { Wave Kintetic Eneregy, } E=\frac{\rho g A^{2}}{2}
$$

Where:

$\rho=$ density of water,

$\mathrm{g}=$ gravitational acceleration

$\mathrm{A}=$ the amplitude of the wave.
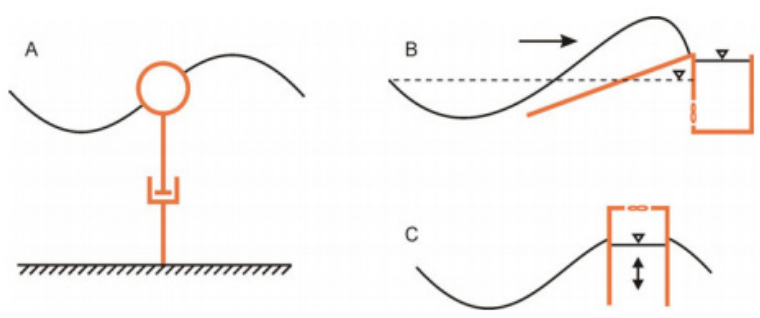

Figure 3. General concepts of capturing wave energy (Lee et al. 2019)

Many concepts are available to convert wave motion to mechanical or electrical energy (Babarit 2017; Leijon et al. 2006). The concepts are illustrated in Figure 3. These are: Wave activated bodies (A), overtopping devices (B) and oscillating water columns (C) (Drew et al. 2009). Wave activated body is the concept where the movement of the wave is translated to the movement of the device (Kim et al. 2019). A noteworthy subcategory of wave activated bodies are point absorbers (Do et al. 2018; Tampier \& Grueter 2017). The main advantage of point absorbers is that they are relatively small in the size and require less space on the ocean surface area. Overtopping devices contain of a ramp or a channel that drives the incoming sea water to rise up and overflow into a reservoir (Fernandez et al. 2012). Since the height of the reservoir water surface has been elevated relative to the ocean surface, the kinetic energy of the sea waves is mostly converted to potential energy (Albert et al. 2017). This design is similar to the hydro power plants where the water is discharge back into the sea through a turbine. Oscillating water columns (OWCs), have an oscillating pillar of water that pumps air through a turbine (Samrat et al. 2014). This motion of the water pillar is achieved by taking a pipe and placing it partly submerged in the sea. The waves that roll against the pipe will make the internal water surface oscillate. This oscillation is normally used to pump air which drives a turbine.

\section{Methodology}

The methodology for this study is shown in Figure 4.

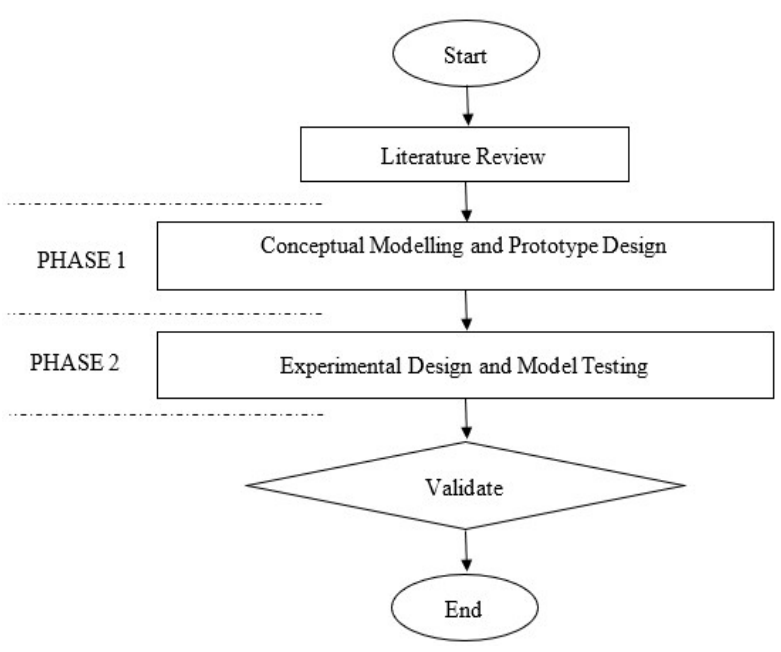

Figure 4. Research methodology

This study started with literature review on the existing wave energy convertor concepts and water pump technologies. A small-scale model is developed based on suitable concept. The prototype is then situated at Mukah Beach, Sarawak for near shore application. The testing period is between March to September when average wave height is less than $1 \mathrm{~m}$ to fit the definition of low height sea waves (Lee et al. 2019). The data collected are analyzed and validated statistically.

\section{Conceptual and Prototype Design}

Based on findings from literature review, point absorber type concept is suitable as most of the wave energy extraction concepts required structural support, large area, funding to start off and bulky. The degree of freedom of sea waves is also the main concern for this study. The typical degree of freedom of a body interacting with waves is shown in Figure 5.

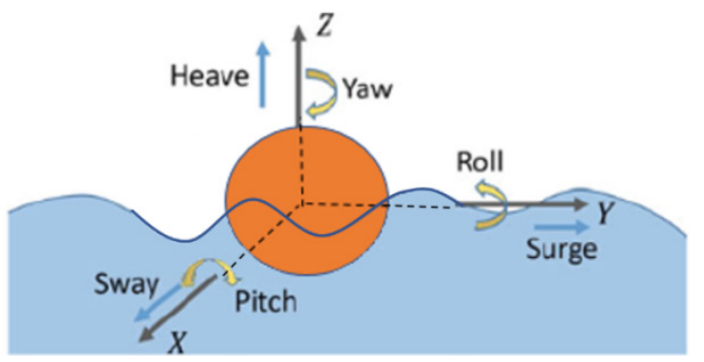

Figure 5. Degree of freedom of a body interacting with waves (Lee et al. 2019) 


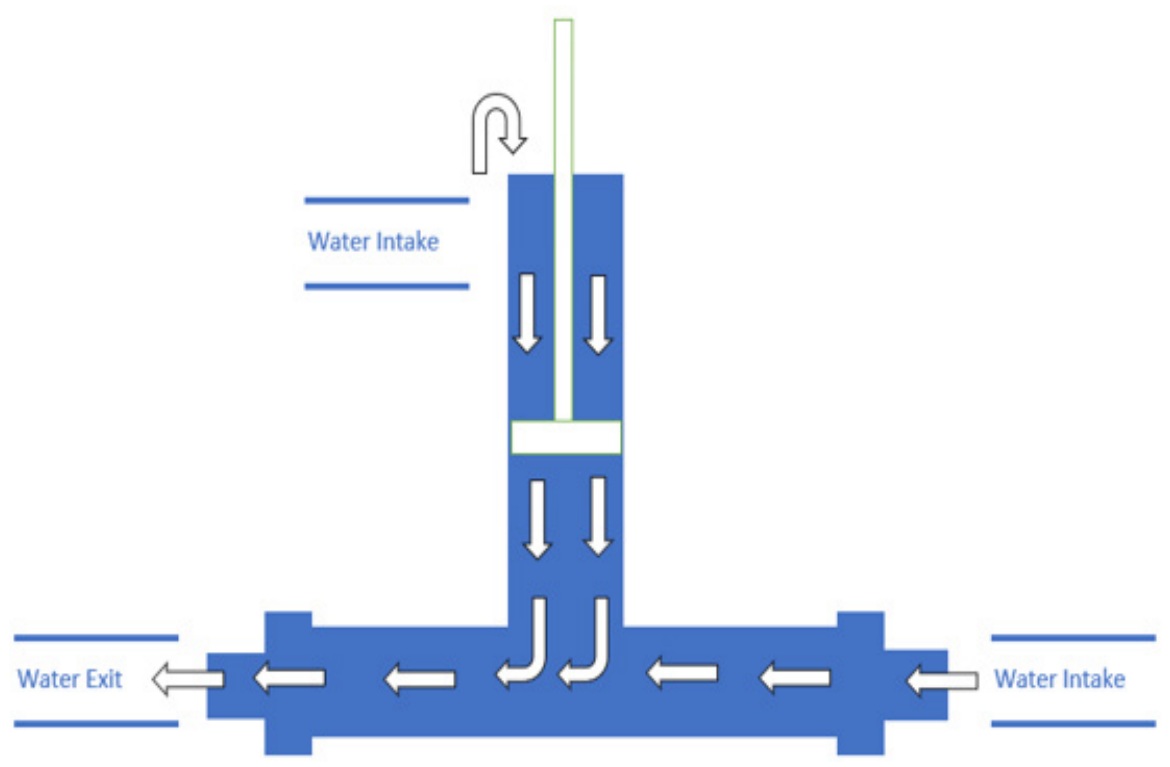

Figure 6a. Flow direction of wave pump

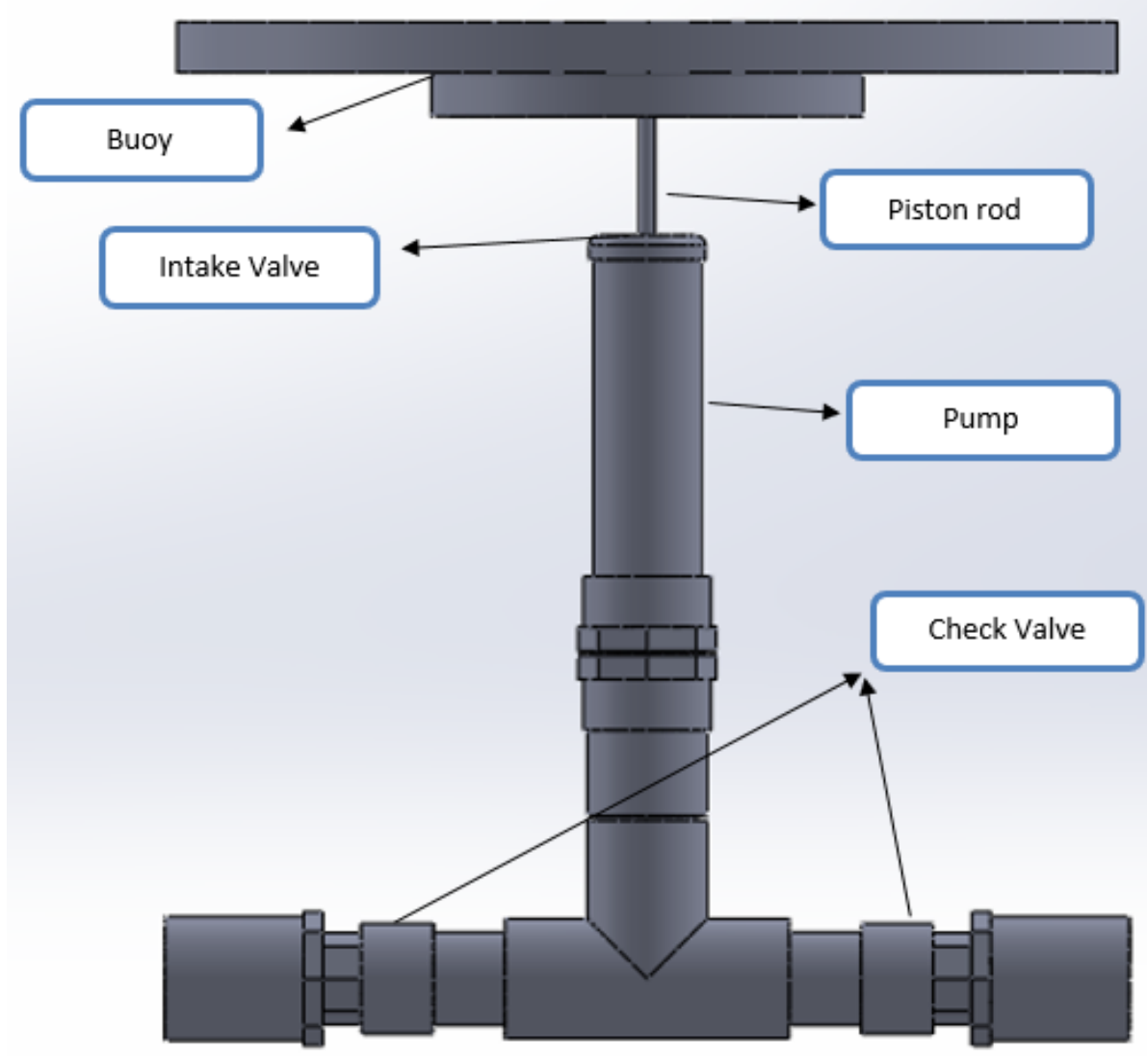

Figure 6b. Conceptual design of wave pump

The point absorber concept utilizes the heave motion of waves and the motion is similar to pumping action of typical hand pump. The conceptual model is shown in Figure 6 along with the fluid flow direction of the concept model.

The design has two intake valves (check valves which only permits one directionala flow to prevent loss of pressure due to back flow) to collect water which allow the pump system to collect the water more quickly and efficiently, and there is only one output valve (check valve) is to compress the fluid to improve the delivery pressure head. After careful selection of the materials, the prototype is developed and shown in Figure 7. 


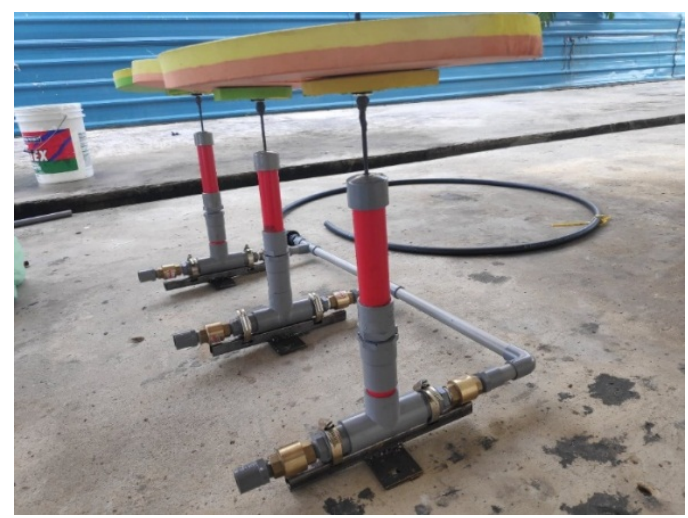

Figure 7a. Pumps connected in parallel

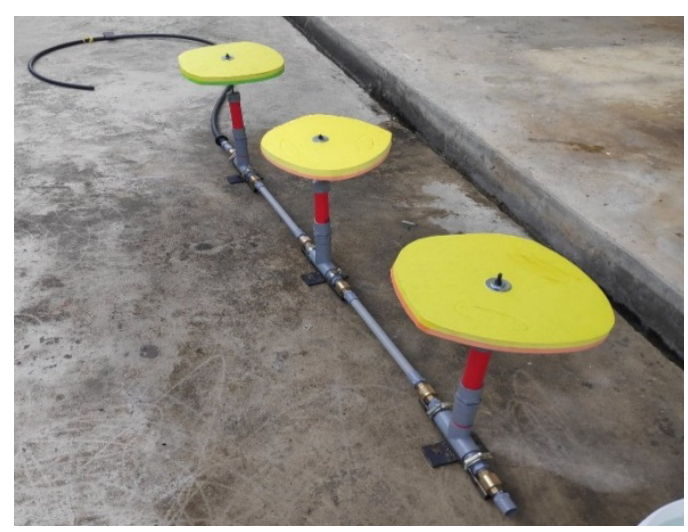

Figure 7b. Pumps connected in series

\section{Results and Discussions}

The prototype is tested in Mukah Beach, Sarawak, between March to June 2019 as this is the time where wave height would be the lowest and not influenced by extreme wave climates due to monsoon season. The average wave height recorded is about $0.5 \mathrm{~m}$ and period of $4 \mathrm{~s}$. The pump performance curves is shown in Figure 8.

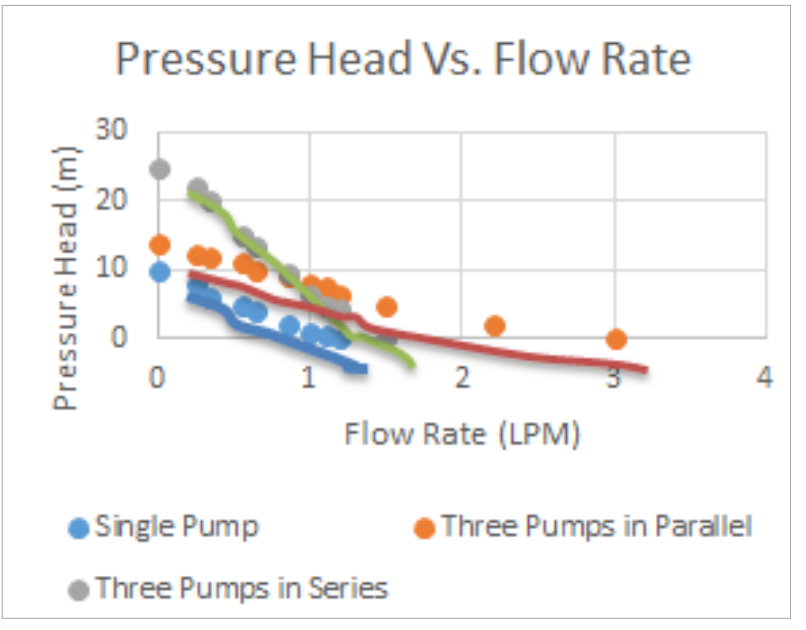

Figure 8. Zero electricty sea water pump curve
Results from Figure 8 show that the single pump is capable to deliver maximum of $10 \mathrm{~m}$ pressure head and up to 1.2LPM of seawater. Meanwhile, for three identical pumps connected in parallel, the maximum recorded pressure head is about $14 \mathrm{~m}$ and 3LPM of maximum flow. On the contrary, for three identical pumps connected in series, the maximum recorded pressure head is about $25 \mathrm{~m}$, and 1.5LPM of flowrate. The findings indicate that tapping energy from low height sea wave to drive a piston pump for delivering water to on shore is possible. Different configurations of the pumps facing the wave fronts will give different results. Pumps comnnected in parallel will give more flow instead of pressure head; pumps in series will produce more head instead of flow. The findings in this study related to the configurations of pumps are inline with standard electrical centrifugal pumps where if connected in series the second pump will act like booster pump to boost the head significantly. Likewise, if centrfugal pumps conntected in series, the system produce more flow significantly than head (El-halwagi, 1992). The point absorber mechanism is significant to allow energy extraction even at low height wave condition (Lee et al. 2019). The performance of this design depends on heave motion of the sea wave (Tampier \& Grueter 2017) (Figure 5). In that aspect, the sea wave amplitude will determine the pressure and flow output per cycle of wave. The design also depends on the wave period. In that sense, the shorter the wave period, the faster the cycle of wave will generate more output per minute (Loon \& Koto 2016). Hence, this design is more suitable for near shore applications as wave period for off shore sea wave is much higher than near shore sea waves. However, the piston size and prototype height can be customized depends on the depth of seawater as shown in Figure 9.

The outcome of this study is useful for the development of remote locations and islands that does not have access to power grid. The design is suitable to deliver water to a reservoir that can be used for hydro power generation. The conceptual model for a small scale power plant is shown in Figure 10. The main advantage of such system would be easy to install and commission as there is no heavy structural design needed or trenches needed to divert water to the reservoir. The pump system is capable of delivering water to the reservoir. The reservoir needed could be just a plastic tank that can paired with micro hydro turbine for efficient hydroelectric generation. As hydro turbines in market today are well established and the efficiency is very high $(>80 \%)$ (Oliver Paish 2002; US Department of the Interior 2005), by applying the concept from this study, more stable energy generation could be harnessed from wave energy.

Apart from that, the seawater stored in reservoir from the wave power plant could be treated to prolong the lifespan of hydroturbines and being transfer to desalination plant for water treatment (Prihasto et al. 2009). This conceptual wave power plant would be useful for solving energy and 
water problem.

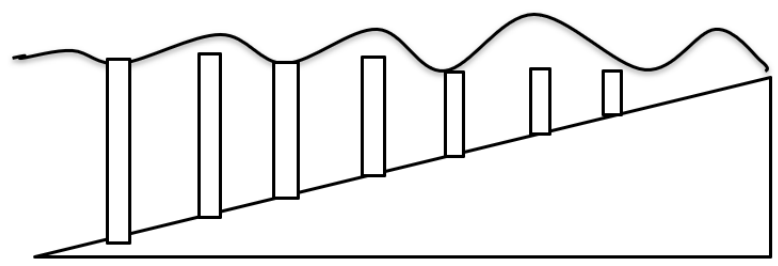

Figure 9. Height of prototype and depth of water

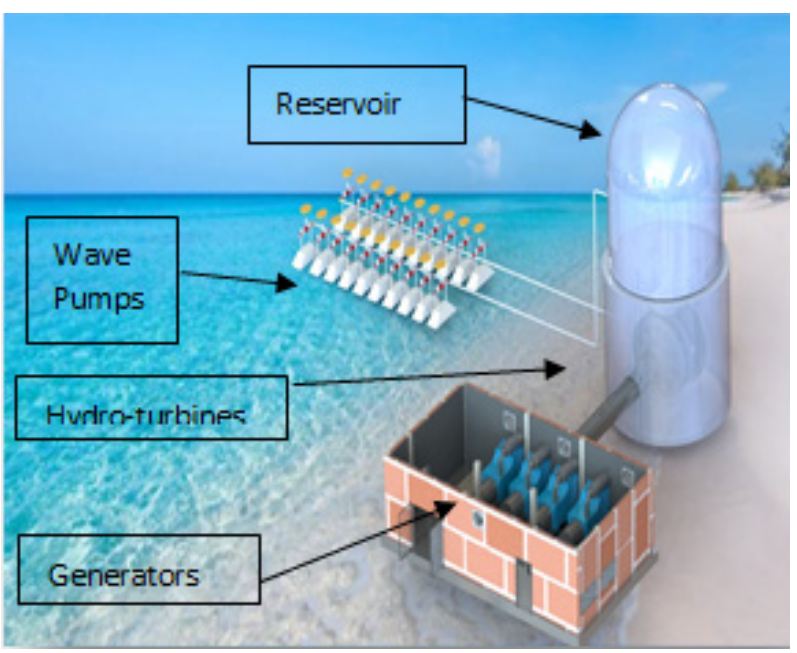

Figure 10. Conceptual wave power plant

\section{Conclusions}

In this study, a prototype for utilizing sea waves as energy source to drive piston pump mechanism is developed. This design utilized point absorber type mechanism to capture the heave motion of sea waves. This type of mechanism is useful for small scale prototyping as no structural support is needed and it is relatively low cost to be built as compared to other means. The sea state of Malaysia coast line is relatively calm compared to other regions around the world. In that aspect, the height of sea waves around Malaysia coastline is classified as low height sea waves which theoretically contains lower wave energy. However, findings of this study indicated that energy extraction to drive a piston pump mechanism is possible with pressure head of $25 \mathrm{~m}$ for three identical pumps connected in series. A maximum of 3LPM flowrate is also being recorded by three pumps connected in parallel. All in all, the main aim of this study is achieved. The outcome of this study is suitable to be used in near shore application as its core performance depends on wave height and wave period. The future direction would be to optimize the current design for more flowrate and pressure. Another direction for future study is to make a hydroelectric generation system which comprised of large number of such pumps.

\section{Acknowledgements}

Authors acknowledged the financial support received from University College of Technology Sarawak, Malaysia under university internal grant scheme (UCTS/research/4/2018/15). Authors are also pleased to offer special thanks to staffs of School of Engineering for their support.

\section{REFERENCES}

[1] Albert, A., Berselli, G., Bruzzone, L. \& Fanghella, P. 2017. Mechanical design and simulation of an onshore four-bar wave energy converter. Renewable Energy 114: 766-774. doi:10.1016/j.renene.2017.07.089

[2] Babarit, A. 2017. Wave Energy Conversion Historical Perspective. Wave Energy Conversion. Uppsala Universitet. Retrieved fromhttps://linkinghub.elsevier.com/retrieve/pii/ B9781785482649500021

[3] Do, H. T., Dang, T. D. \& Ahn, K. K. 2018. A multi-point-absorber wave-energy converter for the stabilization of output power. Ocean Engineering 161(March): 337-349. doi:10.1016/j.oceaneng.2018.03.09 3

[4] Drew, B., Plummer, A. R. \& Sahinkaya, M. N. 2009. A review of wave energy converter technology. Proceedings of the Institution of Mechanical Engineers, Part A: Journal of Power and Energy 223(8): 887-902. doi:10.1243/09576 509JPE782

[5] El-halwagi, M. M. (1992). Synthesis of Reverse-Osmosis Networks for Waste Reduction. AIChE Journal, 38(8), 1185-1198. https://doi.org/10.1002/aic.690380806

[6] Fernandez, H., Iglesias, G., Carballo, R., Castro, A., Fraguela, J. A., Taveira-Pinto, F. \& Sanchez, M. 2012. The new wave energy converter WaveCat: Concept and laboratory tests. Marine Structures 29(1): 58-70. doi:10.1016/j.marstruc.2012.10.002

[7] Hong, Y., Waters, R., Boström, C., Eriksson, M., Engström, J. \& Leijon, M. 2014. Review on electrical control strategies for wave energy converting systems. Renewable and Sustainable Energy Reviews 31: 329-342. doi:10.1016 j.rser.2013.11.053

[8] Illesinghe, S. J., Manasseh, R., Dargaville, R. \& Ooi, A. 2017. Idealized design parameters of Wave Energy Converters in a range of ocean wave climates. International Journal of Marine Energy 19: 55-69. doi:10.1016/j.ijome. 2017.03.003

[9] Joe, H., Roh, H., Cho, H. \& Yu, S. C. 2017. Development of a flap-type mooring-less wave energy harvesing system for sensor buoy. Energy 133: 851-863. doi:10.1016/j.energy.2 017.05.143

[10] Kim, S. soo, Lee, J. chul, Kang, D. \& Lee, S. sup. 2019. Motion characteristics of a floating wave energy converter with wave activating body type. International Journal of Naval Architecture and Ocean Engineering 11(1): 244-255. doi:10.1016/j.ijnaoe.2018.04.005 
[11] Lee, M. D., Ngu, H. J. \& Shin, D. T. Y. 2019. Energy Extraction from Low Height Sea Wave in Sarawak near Shore Region. Open Journal of Optimization 08(01): 47-58. doi:10.4236/ojop.2019.81005

[12] Leijon, M., Danielsson, O., Eriksson, M., Thorburn, K., Bernhoff, H., Isberg, J., Sundberg, J., et al. 2006. An electrical approach to wave energy conversion. Renewable Energy 31(9): 1309-1319. doi:10.1016/j.renene.2005.07.0 09

[13] Loon, S. C. \& Koto, J. 2016. Wave Energy for Electricity Generation in Malaysia -Merang Shore, Terengganu. International Journal of Environmental Research \& Clean Energy 304(1): 8-18. Retrieved from http://isomase.org/IJ ERCE1.php

[14] Oliver Paish. 2002. Small hydro power: technology and current status. Renewable and Sustainable Energy Reviews 6 (2002)(6 (2002)): 537-556. Retrieved from https://dspace.ist.utl.pt/bitstream/2295/296312/1/Paper Small Hydro Power.pdf

[15] Pecher, A. \& Kofoed, J. P. 2017. Handbook of Ocean Wave Energy, hlm. Vol. 7. Switzerland: Springer.doi:10.1007/97 8-3-319-39889-1

[16] Prihasto, N., Liu, Q.-F. \& Kim, S.-H. 2009. Pre-treatment strategies for seawater desalination by reverse osmosis system. Desalination 249(1): 308-316. doi:10.1016/j.desal .2008 .09 .010

[17] Rodrigues, L. 2008. Wave power conversion systems for electrical energy production. Nova university of Lisbon 1(6): 2-3. doi:10.24084/repqj06.380

[18] Samrat, N. H., Ahmad, N. Bin, Choudhury, I. A. \& Taha, Z. 2014. Prospect of wave energy in Malaysia. Proceedings of the 2014 IEEE 8th International Power Engineering and Optimization Conference, PEOCO 2014 (March): 127-132. doi:10.1109/PEOCO.2014.6814412

[19] Tampier, G. \& Grueter, L. 2017. Hydrodynamic analysis of a heaving wave energy converter. International Journal of Marine Energy 19: 304-318. doi:10.1016/j.ijome.2017.08. 007

[20] US Department of the Interior. 2005. Hydroelectric Power. Reclamation: Managing Water in the West. doi:10.1192/bj p.111.479.1009-a

[21] Yurchenko, D. \& Alevras, P. 2018. Parametric pendulum based wave energy converter. Mechanical Systems and Signal Processing 99: 504-515. doi:10.1016/j.ymssp.2017. 06.026 